\title{
PS I want all the rights
}

The debate over whether research results should be freely accessible has always been fraught. Having given a lot of ground, journal publishers are determined to hang on to one last bastion: their rights to the published version of scientific articles. Now librarians and open-access advocates have set their sights on that final prize - by encouraging researchers to demand the right to distribute the published versions freely and immediately.

Funding agencies are increasingly adopting policies to make the results of the research they fund free for all. Both the US National Institutes of Health (NIH) and Britain's Wellcome Trust, for example, encourage this practice. They ask that the version of a manuscript accepted for publication be put in an openaccess library such as PubMed Central within 6-12 months of it coming out. The Wellcome Trust's policy will become compulsory on 1 October, and legislation that would make the $\mathrm{NIH}$ policy mandatory is pending in the US Congress (see Nature 441, 915; 2006).

Ann Wolpert, director of libraries at the Massachusetts Institute of Technology (MIT) in Cambridge, Massachusetts, has launched an initiative that she says will clearly assign rights to the author in a way that would satisfy funders. Wolpert has drawn up a document that researchers can add on to the rights agreement the publisher gives them to sign. Similar agreements have been drafted by the Scholarly Pub-

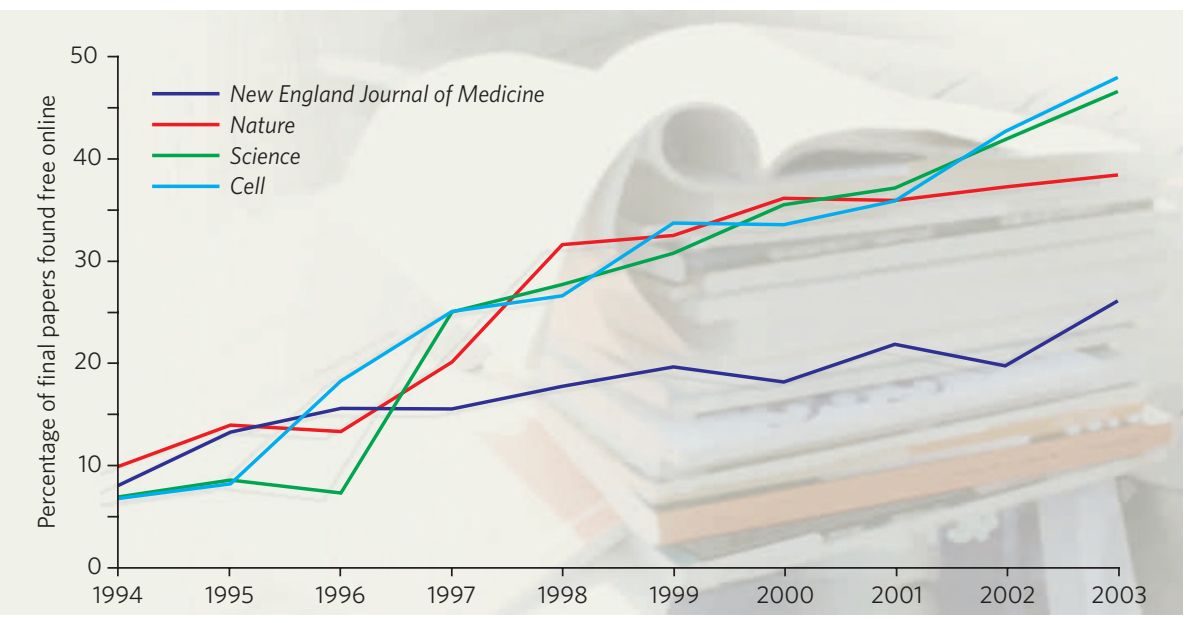

More than a third of authors already post final versions of their science papers online, a $B M J$ study found.

lishing and Academic Resources Coalition and the MIT-affiliated Science Commons.

"I look at it as responding to a request by faculty members to simplify their lives," says Wolpert. "They say it is crazy that we are supposed to read and understand these publishers' agreements. Give me something that I can just staple to any agreement, so I can comply with NIH or Wellcome Trust policy."

But publishers' groups argue that the agreements being drafted go much further than is necessary to comply with current policies. Wolpert's document, for example, would allow authors to publish the final, formatted version of their paper anywhere on the Internet, as many times as they like, immediately after publication. "This isn't a balance of rights. This is giving MIT all the relevant rights," says David Hoole, head of brand marketing at Nature Publishing Group.

Publishers point out that most journals already allow authors to post the accepted version of their paper online, as required by the $\mathrm{NIH}$ and the Wellcome Trust. Such versions have been peer reviewed, but aren't copy-edited, formatted or paginated. But giving authors

\section{City state hopes research cash will buy global status}

Singapore already has a reputation for throwing money at scientists in particular fields it wants to develop. Now, the government says it will almost double its research budget over the next five years, to a hefty $3 \%$ of its gross domestic product (GDP). But whereas those in the favoured fields have welcomed the money, others complain that, as ever, basic research is losing out.

The government announced on 7 July that its newly established National Research Foundation (NRF) will spend $\mathrm{S} \$ 1.4$ billion (US\$876 million) during 2006-10 in three areas: biomedical research; environment and water technologies; and interactive and digital media. This is part of the S\$5-billion five-year budget set aside for the NRF when it was created in January.

Another $\$ \$ 1$ billion is earmarked for a project to attract world-class research institutes. As a start, the NRF says it will establish a joint research centre with the Massachusetts Institute of Technology next year in Singapore, and hire $300-400$ researchers to work there. How the remaining S\$2.6 billion will be spent has yet to be decided.

The announcement represents the first big move in the government's ambitious plan to increase its research and development budget to $\$ \$ 13$ billion for $2006-10$, or $3 \%$ of the country's GDP.

Singapore is famous for big science initiatives, especially in the biomedical sector. One example is Biopolis, a $\$ \$ 500$ million development that houses biotech research institutes and pharmaceutical giants such as Novartis. Next year, the government plans to open the first phase of a Fusionopolis complex, which will house information-technology and media companies.

Despite previous investment, the NRF's chairman, Tony Tan, says the Singaporean government is concerned about keeping its competitive edge in science and technology research, compared with big and growing economies such as those of India and China.

Over the past few years, Tan has travelled to other small but wealthy countries such as Switzerland, Denmark and Sweden to find out how they do it. He says he learned the importance of specializing in a small number of research areas that are likely to turn a profit.

The NRF is now discussing exactly how funds in each of the three research areas will be spent and when to start accepting grant applications. $\$ \$ 550$ million will go towards biomedical research, especially translational and clinical studies - a move from the previous 
rights to the final versions, they say, could make it impossible for journals to earn a living.

Jerry Cowhig, managing director of the publishing arm of the Institute of Physics, says that the institute provides articles free online for 30 days after publication, and that he is happy for authors to post the accepted versions of their papers. But he is not in favour of making the final, edited version of a paper freely available everywhere. "That would be a real threat to the continuation of established journals, and the eventual outcome would be to damage scholarship," he says.

Sally Morris, chief executive of the Association of Learned and Professional Society Publishers, agrees. "The final version is where publishers add value," she says.

On 27 June, Morris's group, along with the International Association of Scientific, Technical and Medical Publishers, wrote to Wolpert outlining their concerns and proposing a meeting. A similar letter went out from the professional and scholarly publishing division of the Association of American Publishers on 7 July.

But would giving authors such rights really damage journals? After all, many authors already post the final version of their paper on the web regardless of what their rights agreement says. A study by Jonathan Wren, a bioinformatician at the University of Oklahoma in Norman (J. D. Wren Br. Med. J. 330, $1128-1131 ; 2005)$, revealed that the final versions of more than one-third of articles in

high-impact journals are freely available online (see graphic).

Ted Bergstrom, an economist at the University of California, Santa Barbara, argues that for libraries and other users, the convenience and authority of journal subscriptions will still be preferable to searching out free versions of papers individually. So agreements such as Wolpert's shouldn't affect the bottom line of any but the most overpriced publications, he says.

Wolpert adds that the value of journals isn't just in locating and reading individual papers, but in browsing and the 'serendipity factor'. "There is value behind a collection of articles judged worth your attention by smart people in your discipline," she says.

John Cox, a consultant to publishers and academic societies who is based in Chichester, UK, says that the value of papers as they

“This isn't a balance of rights. This is giving MIT all the relevant rights."

\section{the screen to the reader."} appear on journal websites is often underestimated. "It's not just the copy-editing, but the infrastructure that is provided: the linking to citations, indexing, alerting services, the presentation of the product on

But he argues that the desire to post final versions across the web is misguided because the version published on the journal website will always be definitive. "It becomes, if you like, part of the minutes of science," he says. "That is deeply embedded in the scientific research culture."

Emma Marris

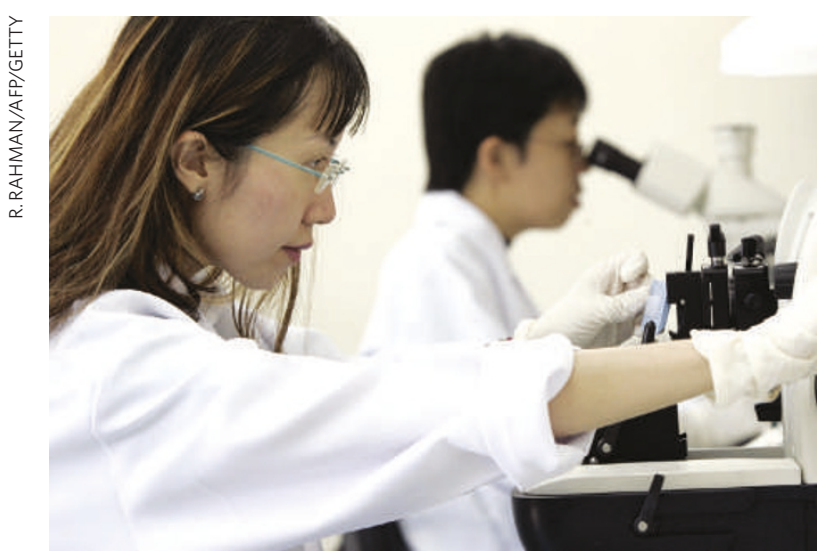

Will investment in research help Singapore keep its competitive edge?

focus on basic research. $\mathbf{\$ 3 3 0}$ million is likely to go towards strengthening technologies that allow the country to produce clean water, for domestic use

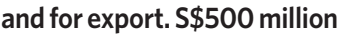
will go towards developing media technologies such as video games and digital cinema. Some academics, such as
Barry Halliwell, deputy president of research and technology at the National University of Singapore (NUS), have acclaimed the funding, saying it will help to attract big names from overseas.

Others are underwhelmed. The NUS's Juan Walford, who studies seahorses as a barometer for the quality of the marine environment, says the new categories are just a reclassification of areas already given the bulk of government money. "There is really nothing new," he says. "It's all applied technology and engineering, there's no new opening for 'scientific research'." Ichiko Fuyuno and David Cyranoski
ON THE RECORD

'CI'll have time for feelings after I'm dead. Right now, we're busy."

NASA administrator Michael Griffin tells reporters how he feels about the successful launch of the space shuttle Discovery on 4 July.

\section{“I am really, really proud. The only problem is that I really don't know what to do with it."}

Stefan Trellenkamp of the University of Kaiserslautern explains how he engraved the world's smallest soccer pitch - 500 nanometres long - on acrylic glass.

Sources: NPR, Reuters

\section{SCORECARD}

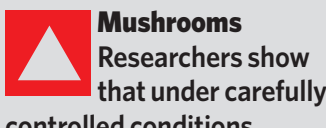
controlled conditions, hallucinogenic mushrooms can cause spiritual experiences that have positive effects on a person.

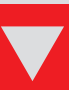

\section{Cannabis}

Neuroscientists reveal that rats given cannabis when they are young are more likely to become addicted to heroin. This suggests that marijuana could make users more susceptible to hard drugs.

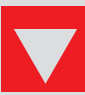

Obesity

A US study of more than 9,000 adults finds that those suffering from obesity are $25 \%$ more likely to have mental health problems.

\section{NUMBER CRUNCH}

Scientists are drowning in paperwork, according to a survey of more than 6,000 US faculty members by the Federal Demonstration Partnership.

$42 \%$ of 'research time' is actually spent doing administration.

4 hours a week could be saved if researchers got administrative help.

$10 \%$ of their research grant is what some scientists say they would be prepared to pay for that help.

Source: Chronicle of Higher Education 